\title{
Minors' tobacco possession law violations and intentions to smoke: implications for tobacco control
}

\author{
N H Gottlieb, A Loukas, M Corrao, A McAlister, C Snell, P P Huang
}

Tobacco Control 2004;13:237-243. doi: 10.1136/tc.2003.003988

See end of article for authors' affiliations

.....................

Correspondence to: Nell H Gottlieb,

$\mathrm{PhD}$, Department of Kinesiology \& Health Education, The University of Texas at Austin, Bellmont Hall 222, Austin, TX 78712, USA; ngottlieb@mail.utexas.edu

Received 21 March 2003 Accepted 17 March 2004
Objectives: To test: (1) whether citation under the Minors in Possession (MIP) law, vicarious citation (knowing someone who was cited), and threat of driving licence suspension are associated with decreased intentions to smoke next year; and (2) whether the policy is differentially enforced.

Subjects: 28249 white, Hispanic, and African American students in grades 6-12 (11-18 years old) participated in the study.

Method: The 86 item anonymous Texas Youth Tobacco Survey was completed by students attending 37 schools in 14 east and central Texas communities.

Results: Hierarchical linear modelling showed that MIP citation was unrelated to the future smoking intentions of most youth. However, there was a negative association between citation and smoking intentions for ever daily smoking youth at four schools. Threat of licence suspension was associated with a lower likelihood of future smoking intentions among ever daily smoking youth and vicarious citation did not deter youth from future smoking. African American and Hispanic youth had a higher probability of being cited than their peers.

Conclusions: Threat of driving licence suspension has the intended effect upon youth who are/were committed smokers and MIP citation has the intended effect upon committed smokers at only four schools. However, differential enforcement of the law based on ethnicity may be occurring. Before drawing firm conclusions, current findings must be replicated with longitudinal data to determine the consequences of citation on subsequent tobacco use.
1: the USA, several regulatory approaches have proven effective in decreasing and deterring substance use among adolescents. ${ }^{1}$ For instance, restrictions on smoking in the home, in public places, and enforcement of school policies prohibiting smoking have resulted in lower tobacco use among youth. ${ }^{2}$ Strong enforcement of minors' access policies that prohibit sales of tobacco to individuals under the age of 18 and penalise vendors for selling tobacco to underage youth have reduced sales to adolescents and also have reduced rates of adolescent smoking. ${ }^{4}$ More recently, some researchers have argued that policies penalising youth for purchasing, using, and/or possessing tobacco may similarly decrease and deter tobacco use. ${ }^{25-7}$ One such set of laws that penalise youth for possessing and using tobacco is the Minors in Possession (MIP) laws.

MIP laws make it a non-criminal offence for individuals under the age of 18 years to use or possess the substance. Although all states with such laws have 18 as the minimum smoking age, MIP laws vary considerably across states, counties, and municipalities in content and level of enforcement. ${ }^{28}$ Typically, sanctions/penalties for violating MIP policies include fines, community service, tobacco awareness and education classes, as well as licence suspension. Laws vary in fine amounts, types and length of community service, length and content of tobacco awareness class, etc. The MIP law passed by the Texas Legislature in $1997^{\circ}$ provides for citations by law enforcement officers, resulting in a fine, tobacco awareness class referral and/or community service for offenders. Comprised of four, 2 hour sessions, awareness classes help youth create a level of dissatisfaction with their own smoking and provide information about health effects, tobacco advertising strategies, and costs of tobacco. ${ }^{10}$ Minors who fail to comply with court orders may have their drivers' licences suspended for 180 days depending on judiciary discretion. In the present study, we examined the role of MIP citation in the smoking behaviour of Texas youth.

From a social cognitive theory $(\mathrm{SCT})^{11}$ perspective, MIP policies reduce or deter substance use by fostering an environment in which smoking by minors is unacceptable. In particular, it is the potential punishment associated with violating the policy that deters and decreases subsequent tobacco use. Threat of licence suspension may be one legal sanction that would serve to encourage adolescents to quit smoking or to discourage adolescents from intending to smoke. Moreover, from this perspective, observing peers and valued individuals being cited for possession may also encourage youth to quit smoking or deter them from intending to smoke because of the vicarious threat of also being cited. Deterrence theory similarly suggests that the legal and social sanctions resulting from MIP citation should deter adolescents from smoking. ${ }^{12}$

Although MIP laws are in place in 33 states, ${ }^{13}$ to date few studies have empirically evaluated the consequences of MIP citation. Langer and Warheit ${ }^{14}$ interviewed $12-17$ year old Florida teens cited for tobacco possession about their tobacco use upon appearance at a special tobacco court (wave 1) and also two months following appearance (wave 2). Results showed that upon appearance at tobacco court, $16 \%$ of youth reported ceasing tobacco use and $28 \%$ reported using less. The largest change in use was by $12-14$ year olds with one half reporting not using tobacco since citation (32\%) or using less (18\%). Tobacco use declined even further for the $40 \%$ of

Abbreviations: HLM, hierarchical linear modelling; ICC, intraclass correlation coefficient; MIP, Minors in Possession; SCT, social cognitive theory; TATU, Teens Against Tobacco Use; TNT, Toward No Tobacco Use; YTS, Youth Tobacco Survey 
youth participating in wave 2 of the study. Livingood and his colleagues ${ }^{6}$ compared beliefs and behaviour related to tobacco use among youth living in six Florida counties high or low in MIP enforcement. They found $4-5 \%$ fewer middle and high school youth using tobacco in high enforcement counties and an odds ratio of 0.8 for enforcement, with grade and ethnicity controlled. However, these researchers found that student age and smoking status moderated the impact of potential penalties associated with possession violations. Sixty four per cent of middle school students in comparison to $42 \%$ of participating high school students said they definitely or probably would be less likely to use tobacco because of potential penalties. Moreover, $49 \%$ of youth who smoked one or fewer cigarettes per day reported being less likely to smoke because of penalties in comparison to $23 \%$ who smoked two or more cigarettes per day, and $18 \%$ of those who smoked on the day of the survey. Thus, the law may be more effective in deterring tobacco use among younger, less committed smokers.

The public health community has shown ambivalence toward minors' possession law strategies. The Centers for Disease Control and Prevention ${ }^{15}$ and the Task Force on Community Preventive Services ${ }^{16}$ did not include minors' possession laws in their recommendations. Pentz and colleagues ${ }^{17}$ agree with supporters that no-use policies such as MIP may reinforce prevention and control efforts by fostering an anti-smoking social climate, but they question their usefulness because implementation and enforcement is widely variable, even within the same community. No-use policies also raise ethical considerations such as the possible differential treatment of youth based on other problem behaviours $^{17}$ or individual characteristics such as race/ ethnicity ${ }^{18-20}$ Other criticisms of MIP laws are that they place the blame on the victims of the tobacco industry, rather than the industry itself, ${ }^{21}$ divert attention from tobacco industry marketing, or divert attention from other, more effective tobacco prevention and control programmes ${ }^{22}$ and interfere with informal social controls of society, such as parents. ${ }^{17} 23$ Still others worry that MIP policies have the potential to criminalise tobacco use, ${ }^{21} 23$ resulting in negative social consequences, such as adoption by youth of a deviant self image or future antisocial and deviant behaviour. According to labelling theory, punishing and, in particular, formally adjudicating an individual for a behaviour may result in increased levels of that and other deviant behaviours, in part because the punished individual increasingly identifies with the label. ${ }^{24}$ Thus, minors cited for possession may continue to smoke-an unintended consequence of citation-because they accept the label of smoker.

The purpose of the current study was to extend existing research by: (1) assessing the role of MIP citation, vicarious citation (that is, knowing someone who received a citation) and threat of licence suspension on youths' future intentions to smoke; and (2) examining whether the MIP policy was being differentially enforced. Given that youth who are tolerant of deviance may be more likely than their peers to intend to smoke, ${ }^{25}$ we also assessed whether tolerance for smoking related deviance exacerbated the impact of citation receipt, vicarious citation, and threat of licence suspension on future smoking intentions. Using a population based sample of Texas middle school and high school students, the following questions were addressed: (1) does citation receipt serve as a punishment for smoking; (2) do threat of licence suspension and vicarious citation serve to deter students from future smoking; (3) does tolerance for smoking related deviance moderate the relationships between future smoking intentions and MIP citation, threat of licence suspension, and vicarious citation; and (4) is the MIP policy differentially enforced across ethnicity?

\section{METHODS}

\section{Participants}

Participants were 2824911 to 18 year old (mean (SD) age 14.27 (1.95) years), white (45.9\%), Hispanic (34.1\%), and African American (20\%) students attending 37 sampled schools in 14 east and central Texas communities. Slightly over half $(51.5 \%)$ were female. Participants who indicated they were Asian or Other ethnicity $(n=3806)$ were not included because of underrepresentation and non-specificity of the Other category. Data from an additional 117 students were not included in the current study because of missing or contradictory information on smoking status. Analyses conducted to determine whether the 117 students not included in the study differed from the 28249 included students on study variables showed that the students not included in the study had more friends who smoked, were older, were less likely to be threatened by citation, more likely to intend to smoke next year, more likely to live in a home with a smoker, and more likely to be Hispanic than white. No differences were found between the two groups on probability of citation, vicarious citation, level of tolerance for smoking related deviance, amount smoked in lifetime, and African American versus white ethnicity.

\section{Procedures}

Data for the current study were drawn from students attending 37 schools (59\% middle schools) participating in the follow up Texas Youth Tobacco Survey (YTS), ${ }^{26}$ administered in November and December of 2000. Although 42 of the largest and most ethnically diverse schools in the study areas participated in the baseline Texas YTS in January and February of 2000, five schools refused participation in the follow up survey. Refusal schools were replaced by 11 other schools using a protocol from a list ordered by enrolment size and diversity. Data from the 11 replacement schools were not included in the present study because youth participation rates were substantially lower than those for youth from the 37 sampled schools. Students present on the day of the follow up administration voluntarily completed an anonymous 86 item questionnaire regarding tobacco use administered by classroom teachers. Participation rates across the 37 schools averaged $70 \%$ (range $32-90 \%$ ).

The follow up survey occurred after various tobacco preventive interventions were delivered during the summer and fall (autumn) of 2000 through the state's Tobacco Settlement Pilot Project. Intervention components included a low level media campaign equivalent to approximately $\$ 0.50$ in annual per capita implementation costs, a high level media campaign equivalent to approximately $\$ 1.00$ in annual per capita implementation costs, law enforcement programmes that provided funds to increase enforcement of youth access and possession laws, cessation activities educating health care providers about current clinical practice guidelines for treating tobacco use and in how to identify and assist patients in ceasing tobacco use, and community and school programmes encouraging the development of tobacco centred coalitions and the use of Project TNT (Toward No Tobacco Use) curriculum in middle schools and TATU (Teens Against Tobacco Use) in high schools. Communities received either: (1) no intervention components; (2) one of the three nonmedia intervention components; (3) a combination of low level media campaigns and one additional component; (4) a combination of high media campaigns and one additional component; (5) a comprehensive approach including high level media campaigns, enforcement, cessation programmes, and school and community programmes.

\section{Measures}

Demographic variables included sex, age, and ethnicity. Ethnicity was measured as "How do you describe yourself? 
(If you come from more than one group, choose the one group that is closest to you. Choose one answer only.)." Only the categories "White or Anglo, not Hispanic"; "White or European descent, not Anglo or Hispanic"; "Black, not Hispanic, Mexican or Mexican-American"; "Other Hispanic or Latino" were coded in the present study.

Several items operationalised youth smoking. ${ }^{27}$ Individual's smoking status was computed using two items: (1) "Have you ever tried cigarette smoking, even one or two puffs?"; and (2) "Have you ever smoked cigarettes daily, that is, at least one cigarette every day for 30 days?". Each item was scored as 0 ("No") or 1 ("Yes"). Youth who never tried smoking were categorised as non-smokers (51.2\%); youth who tried smoking but had not smoked cigarettes daily were categorised as experimental smokers $(28.1 \%)$, and youth who smoked daily $(20.7 \%)$ for a 30 day period were categorised as ever-daily smokers. Amount of cigarettes smoked was measured by "About how many cigarettes have you smoked in your life" and was coded on an eight point scale ranging from 0 ("None") to 8 ("100+ cigarettes"). Intention to smoke at any time during next year was measured as "Do you think you will smoke a cigarette at any time during the next year?" with categories recoded as 0 ("Definitely not" or "Probably not") and 1 ("Definitely yes" or "Probably yes").

Social environment for smoking was operationalised by household smoking and number of smoking friends. Household smoking was measured by "Besides yourself, does anyone who lives in your home smoke cigarettes now?" and scored 0 ("No") or 1 ("Yes"). Number of friends who smoke was measured by "How many of your four closest friends smoke cigarettes?" and scored from 0 ("None") to 4 ("Four").

Tolerance for deviance related to smoking was the mean of three items adapted from Jessor and Jessor's tolerance for deviance scale ${ }^{25}$ and scored on a scale from 1 ("Very wrong") to 5 ("Not wrong at all"): "How wrong is it to lie to parents/ teachers about smoking?"; "How wrong would it be to get cigarettes by stealing them?"; "How wrong would it be to smoke on school grounds even though it is not allowed?".

Citation and its effects were measured using three items. Citation for minors' possession was measured as "Have you received a ticket for using or possessing tobacco products?" and scored 0 ("No") or 1 ("Yes"). Three per cent of females and $6.6 \%$ of males reported receiving a citation. Deterrence was measured by "Would the possibility of losing your driver's licence if you are caught in possession of tobacco products?": 1 ("Make you not want to smoke"); 2 ("Make you think about not smoking"); or 3 ("Not have any impact"). This item was recoded so that 1 and 2 were scored as " 1 " and 3 was scored as " 0 ". The majority of students (77.0\% of males and $82.1 \%$ of females) reported that threat of licence suspension would make them think about not smoking or would make them not smoke. Vicarious MIP citation was assessed with "Do you know anyone who has received a ticket for using or possessing tobacco products?" (recoded $0=$ "No" and $1=$ "Yes"). Thirty one per cent of females and $33 \%$ of males reported knowing someone who received a ticket.

Two variables were included in the models to examine the role of school level smoking prevalence and to partial out the effects of whether or not the school received a tobacco prevention programme. Prevalence of school level smoking was computed using the percentage of students within each school indicating they smoked cigarettes on at least one day in the past month. Whether or not the school received a tobacco prevention program (Project TNT for middle schools or TATU for high schools) was measured by a dichotomous variable coded 0 ("No") or 1 ("Yes").

\section{Analyses}

All study questions were addressed using hierarchical linear modelling (HLM) and the HLM program. ${ }^{28}$ HLM allows examination of clustered data (28 249 students nested within 37 schools) and simultaneously models the school level (that is, prevalence of current smoking students within each school and whether students received a prevention programme) and individual level factors that may impact individual smoking behaviours. Because probability of future smoking intentions is a dichotomous outcome variable, hierarchical generalised linear models were tested to accommodate its non-normal distribution. Separate HLM models were tested by smoking status (non-smokers, experimental smokers, ever-daily smokers) and the effects of MIP citation on future smoking intentions were examined only for students reporting ever smoking - that is, for experimental and ever-daily smokers.

\section{RESULTS}

Before testing study hypotheses, analyses were conducted to examine the proportion of the variance in the smoking intentions outcome due to within subjects variability (that is, to the clustering of students within schools). Intraclass correlation coefficients (ICCs) calculated from the unconditional or "empty" models (that is, model with no covariates) showed that the ICCs ranged from 0.01-0.11. Although these values are small, non-zero ICCs have been shown to bias significantly the results of traditional single level analyses ${ }^{29}$ and indicate that multilevel modelling techniques are appropriate.

To assess the punishment effects of MIP citation and the deterrent effects of threat of licence suspension and vicarious citation, the unique contributions of each independent variable were examined for intention to smoke next year, controlling for school level prevalence of current smoking, whether or not the school received a tobacco prevention programme, and individual level sociodemographic, smoking, and smoking related contextual covariates. Two way interactions of tolerance for smoking related deviance with threat of licence suspension, MIP citation (for experimental and ever daily smokers only), and vicarious citation tested whether the effects of deterrence, citation, and vicarious citation varied for students with high (1 SD above mean) and low (1 SD below mean) levels of tolerance for deviance. We also tested two way interactions between sex and all main effect predictor variables and three way interactions between sex, tolerance for deviance and either citation, vicarious citation, or threat of licence suspension. These latter interactions tested differences between males and females on all study variables and on the two way interactions involving tolerance for smoking related deviance. Interactions were examined individually in separate models with all predictor variables included. To eliminate problems with multicollinearity, all continuous variables included in interaction terms were centred. All significant interactions were probed using the methods of Aiken and West ${ }^{30}$ and nonsignificant interactions were trimmed from the final models.

Table 1 shows the odds ratios (OR) and 95\% confidence intervals (CI) for the final HLM models. Minors in possession citation receipt was not uniquely associated with a lower probability of smoking next year for experimental or everdaily smokers, and there were no interactions between MIP citation and tolerance for smoking related deviance. Examination of the variance component of the models, however, showed that among ever-daily smokers, there was a significant amount of variability around the MIP citation effect (variance estimate $0.48, \mathrm{p}<0.05$ ). This result indicates that the nature of the relation between MIP citation and smoking intention varies significantly across the 37 sampled schools. Given this finding, 37 follow up logistic regression 
Table 1 Odds ratios and $95 \%$ confidence intervals (OR, 95\% Cl) for receipt of citation, vicarious citation, threat of driving licence suspension, sociodemographic, smoking, and smoking related influences predicting intentions to smoke next year for non-smokers, experimental smokers, and ever-daily smokers $(n=28249)$

\begin{tabular}{|c|c|c|c|}
\hline Variable & $\begin{array}{l}\text { Non-smokers } \\
\text { OR }(95 \% \mathrm{CI}) \\
(\mathrm{n}=14473)\end{array}$ & $\begin{array}{l}\text { Experimental smokers } \\
\text { OR }(95 \% \mathrm{Cl}) \\
(\mathrm{n}=7929)\end{array}$ & $\begin{array}{l}\text { Ever-daily smokers } \\
\text { OR }(95 \% \mathrm{CI}) \\
(\mathrm{n}=5847)\end{array}$ \\
\hline \multicolumn{4}{|l|}{ School level effects } \\
\hline Percentage current smokers & $1.00(0.98$ to 1.01$)$ & $0.99(0.97$ to 1.01$)$ & $1.00(0.98$ to 1.02$)$ \\
\hline *School prevention programme & $1.01(0.75$ to 1.36$)$ & $1.15(0.98$ to 1.34$)$ & $0.97(0.80$ to 1.18$)$ \\
\hline \multicolumn{4}{|l|}{ Individual level effects } \\
\hline †Sex & $1.05(0.83$ to 1.33$)$ & $0.74(0.63$ to 0.87$)$ & $0.77(0.63$ to 0.94$)$ \\
\hline Age (years) & $0.92(0.85$ to 0.99$)$ & $0.84(0.80$ to 0.89$)$ & $1.03(0.95$ to 1.11$)$ \\
\hline$\ddagger$ African American & $0.90(0.64$ to 1.29$)$ & $1.12(0.90$ to 1.38$)$ & $0.44(0.34$ to 0.59$)$ \\
\hline$\S$ Hispanic & 1.65 (1.25 to 2.16$)$ & 1.75 (1.47 to 2.09$)$ & 0.75 (0.60 to 0.93$)$ \\
\hline Amount smoked & - & 1.43 (1.38 to 1.49$)$ & 1.45 (1.37 to 1.54$)$ \\
\hline Household smoking & $1.30(1.03$ to 1.64$)$ & $0.98(0.84$ to 1.15$)$ & $1.17(0.96$ to 1.43$)$ \\
\hline Number of friends who smoke & $1.52(1.41$ to 1.65$)$ & $1.32(1.25$ to 1.40$)$ & $1.31(1.24$ to 1.39$)$ \\
\hline Tolerance for smoking related deviance & $1.39(1.33$ to 1.45$)$ & 1.27 (1.22 to 1.32$)$ & $1.14(1.10$ to 1.18$)$ \\
\hline Threat of licence suspension & $1.11(0.77$ to 1.62$)$ & $1.00(0.82$ to 1.22$)$ & $0.70(0.57$ to 0.88$)$ \\
\hline Vicarious MIP citation & 2.13 (1.69 to 2.17$)$ & $1.01(0.86$ to 1.18$)$ & $1.12(0.92$ to 1.36$)$ \\
\hline MIP citation & - & $1.07(0.70$ to 1.65$)$ & $0.70(0.47$ to 1.07$)$ \\
\hline Tolerance $\times$ threat of licence suspension & 1.15 (1.04 to 1.27$)$ & NA & NA \\
\hline Tolerance $\times$ vicarious MIP citation & $1.17(1.09$ to 1.27$)$ & $0.92(0.87$ to 0.98$)$ & NA \\
\hline \multicolumn{4}{|c|}{$\begin{array}{l}\text { NA, confidence interval included the value of } 1.0 \text { and therefore was not interpreted. } \\
{ }^{*} \text { Coded } 0=\text { no prevention programme } / 1=\text { prevention programme. } \\
\dagger \text { Coded } 0=\text { female } / 1=\text { male. } \\
\text { †Dummy coded } 0=\text { non-African American } / 1=\text { African American. } \\
\S \text { Coded } 0=\text { non-Hispanic } / 1=\text { Hispanic. }\end{array}$} \\
\hline
\end{tabular}

analyses were conducted to examine the nature of the relation between citation receipt and smoking intentions (with all study variables included) for each school. Results showed that, although there was no relation between MIP citation and smoking intentions for youth at most schools, there was a negative association between citation and smoking intention for youth attending four schools. Among students attending these four schools, receipt of a citation was associated with a lower probability of smoking next year.

Further results showed an independent deterrent effect of threat of licence suspension for ever-daily smokers. Everdaily smokers who reported that licence suspension would make them think about not smoking or not want to smoke had a lower probability of intending to smoke next year. Although threat of licence suspension was not uniquely associated with the smoking intentions of non-smokers, there was a two way interaction between threat of licence suspension and tolerance for smoking related deviance among this group of youth. Probing the interaction showed threat of licence suspension was associated with an increased

Table 2 Odds ratios and 95\% confidence intervals (OR, $95 \% \mathrm{CI}$ ) for race, sex, smoking, and smoking related influences predicting probability of receipt of citation for all students $(n=28249)$

\begin{tabular}{|c|c|}
\hline Variable & OR $(95 \% \mathrm{CI})$ \\
\hline \multicolumn{2}{|l|}{ School level effects } \\
\hline Percentage current smokers & 0.99 (0.97 to 1.01$)$ \\
\hline${ }^{*}$ School prevention programme & $1.19(0.96$ to 1.47$)$ \\
\hline Individual level effects & $1.99(1.77$ to 2.47$)$ \\
\hline Amount smoked & 1.45 (1.42 to 1.48$)$ \\
\hline$\ddagger$ African American & $1.70(1.34$ to 2.15$)$ \\
\hline$\S$ Hispanic & 1.34 (1.12 to 1.59$)$ \\
\hline \multicolumn{2}{|c|}{$\begin{array}{l}{ }^{*} \text { Coded } 0=\text { no prevention programme } / 1=\text { prevention programme. } \\
\dagger \text { Coded } 0=\text { female } / 1=\text { male. } \\
\ddagger \text { } \\
\S \text { Dummy coded } 0=\text { non-African American } / 1=\text { African American. } \\
\S \text { Coded } 0=\text { non-Hispanic } / 1=\text { Hispanic. }\end{array}$} \\
\hline
\end{tabular}

probability of smoking intentions for non-smoking youth low in tolerance for smoking related deviance (OR 1.84, 95\% CI 0.31 to 0.96 ), but not for their peers high in tolerance for smoking related deviance (OR 1.19, 95\% CI 0.83 to 1.69 ).

With respect to the effects of vicarious citation, there was an independent positive association between vicarious citation and smoking intentions for non-smoking male and female adolescents. However, this main effect relation was qualified by a significant two way interaction with tolerance for smoking related deviance. Follow up analyses showed that among youth high in tolerance for smoking related deviance, vicarious citation was associated with an increased probability of smoking next year (OR 2.20, 95\% CI 1.70 to 2.84). Among peers low in tolerance for smoking related deviance, there was no association between vicarious citation and probability of smoking intentions (OR 1.20, 95\% CI 0.80 to 1.77). Further findings showed that although there was no independent deterrent effect of vicarious citation on smoking intentions for experimental smokers, there was a significant interaction with tolerance for smoking related deviance. Probing the interaction indicated that vicarious citation was associated with an increased probability of smoking next year for experimental smokers low in tolerance for deviance (OR $1.34,95 \%$ CI 1.01 to 1.81 ), but not for their high in tolerance for smoking related deviance peers (OR 0.81, 95\% CI 0.64 to $1.04)$.

School level prevalence of current smoking and whether or not the school received tobacco prevention programming were unrelated to the smoking intentions of all groups of students. Other individual level variables positively associated with intention to smoke were amount smoked, tolerance for smoking related deviance, and number of friends who smoked. Female sex was associated with a lower probability of smoking next year among experimental and ever-daily smokers. Moreover, older non-smoking and experimental smoking youth had a lower probability of intending to smoke next year. Finally, in comparison to their peers, non-smoking and experimental smoking Hispanic youth had a higher probability of smoking intentions. Everdaily smoking Hispanic and African American students had a 
lower probability of smoking next year than their white counterparts.

The final study question, differential enforcement of the MIP policy, was tested with one HLM model assessing the probability of citation receipt. The two school level covariates, prevalence of smoking and receipt of tobacco prevention programming, were added to the model as were the individual level variables of sex, amount smoked in lifetime, and race/ethnicity (represented by two dummy variables). This analysis tested whether race/ethnicity was associated with citation receipt, even after the variance associated with sex and amount smoked was partialled out. As can be seen in table 2, in comparison to white race, African American and Hispanic race/ethnicity were associated with an increased probability of citation receipt. After amount smoked was taken into account, minority youth reported being more likely to be cited for tobacco citation than their white peers. These findings suggest that differential enforcement of the law may be occurring.

\section{DISCUSSION}

Despite controversy and lack of empirical research regarding the effectiveness of citing minors for possession of tobacco, 33 states have MIP laws. ${ }^{13}$ The present study aimed to examine the role of MIP citation receipt, vicarious citation, and threat of driving licence suspension on youths' future smoking intentions. The study also assessed whether differential enforcement of the law was occurring. Contrary to deterrence theory ${ }^{12}$ and $\mathrm{SCT},{ }^{11}$ self reported citation receipt was not associated with a lower probability of future smoking intentions for experimental smokers or for most ever-daily smokers. Citation receipt did, however, have the intended punishment effect for ever-daily smoking youth attending four of the 37 sampled schools, underscoring the importance of examining differential effects of citation across school and community contexts-that is, the punishment effects observed at the four schools may have resulted because of factors specific to those contexts. For example, communities and schools with strong enforcement of tobacco policies show greater reductions in youth tobacco use than do communities and schools with irregular enforcement. ${ }^{35}$

Threat of licence suspension was associated with a lower likelihood of future smoking intentions for ever-daily smoking youth, the group most at risk for citation and for whom the law would be most salient. Consistent with deterrence theory ${ }^{12}$ and with SCT, ${ }^{11}$ results indicate that knowledge of the consequences for violating the MIP law may deter youth from continuing to smoke cigarettes. Publicising this consequence may also foster an environment in which smoking is unacceptable. Threat of licence suspension may, therefore, be a policy that has the potential to motivate a decrease in current tobacco use and tobacco cessation among committed smokers.

Threat of licence suspension was not associated with the future smoking intentions of non-smoking youth high in tolerance for deviance or for youth reporting experimental smoking. Perhaps these youth lack knowledge of the law or the law lacks salience for these youth. Clearly, for the deterrent effect to occur, youth must know the consequences of citation under the law. Therefore, publicising the law's provisions would be important. However, our research also showed that non-smoking youth low in tolerance for deviance were more likely to intend to smoke next year if they reported that licence suspension would make them think about not smoking or make them not smoke. These results are contrary to those reported for experimental and ever-daily smoking youth but corroborate prior research showing that youth who are most likely to identify with the deviant label (that is, smoker) are those youth who are the least deviant. ${ }^{31}$ According to Kaplan and Lin, ${ }^{31}$ the real or imagined reactions by others that serve as punishments may lead to an increased propensity to engage in the deviant behaviour because the individual who is being punished increases motivation to deviate from conventional norms, to associate with deviant peers, and to re-evaluate their identities and behaviours. Negative social sanctions often have the strongest effect on youth who are low in tolerance for deviance as it is for these youth that negative social sanctions are most likely to induce feelings of self rejection motivating acceptance of the "deviant" label. ${ }^{31}{ }^{32}$ This explanation may also be appropriate for findings showing that vicarious citation was associated with an increased probability of smoking next year among experimental smokers low in deviance. However, given the lack of research examining the complex nature of the effects of citation on youth smoking behaviours, subsequent research is needed before firm conclusions are drawn from the current data.

Further findings showed that vicarious citation did not have a vicarious punishment effect on the future smoking intentions of students reporting ever-daily smoking. However, vicarious citation was associated with an increased intention to smoke next year among non-smoking youth high in tolerance for deviance. In comparison to their peers, youth who are high in tolerance for deviance are less conventional, more likely to associate with other deviant peers, and to experiment with and use tobacco and other illegal drugs. ${ }^{25}$ It is not surprising, therefore, that these youth are not deterred from future smoking based on their peers' citations.

With respect to the effects of school level factors, neither prevalence of smoking nor availability of a school level tobacco prevention programme was related to youths' smoking intentions. The lack of effect for school level smoking prevalence may have resulted from controlling for the number of friends who smoked, a variable that likely is a better predictor of individual smoking. In fact, Moore and his colleagues, ${ }^{3}$ using data from 11 th grade students attending one of 200 schools, showed that $45 \%$ of within school variation in weekly smoking and $75 \%$ of within school variation in daily smoking was accounted for by best friend's smoking status. Exposure to a tobacco prevention programme at the school also was unrelated to individual smoking behaviours. This finding is not unexpected, however, as others have reported that even high quality school prevention programmes (defined by strong programme intensity, strong focus on tobacco, staff resources designated for prevention programme, and implementation of the Centers for Disease Control and Prevention recommendations for tobacco prevention) were not sufficient to change the smoking behaviours of middle school students. ${ }^{33}$ In the present study, the lack of school level prevention effects may have resulted from the fact that the prevention programme was implemented only three months before administration of the survey, clearly not enough time to change the behaviours of participating youth.

Results from the current research also showed that differential enforcement of the law may be occurring, with African American and Hispanic youth reporting a higher probability of citation than white youth. Consistent with speculations that MIP laws may be used to target certain youth, ${ }^{17}$ these findings are mirrored in arrest statistics and court processing for many types of crime. ${ }^{34}$ As labelling theory would suggest, racial stereotypes may underlie these discrepancies, as minorities are more likely to be labelled as deviant. ${ }^{34}{ }^{35}$ The differential treatment of youth under this law should be addressed by policy and law enforcement officials. However, given that data for this study were based on self reports of citation receipt, further research using 


\section{What this paper adds}

Thirty three states in the USA have passed Minor in Possession laws that make it a non-criminal violation for persons under 18 years to possess a tobacco product. However, little is known about the effect of these laws on youth smoking. One Florida study found lower tobacco use among those cited and attending tobacco court. No studies to date have examined the impact of citations in a population based study of middle and high school students.

The current study examined the contributions of citation, vicarious citation, and threat of driving licence suspension to the future smoking intentions of students in grades 6-12 attending 37 sampled schools in Texas. Findings showed that citation was associated with a lower probability of future smoking intentions only for ever-daily smoking youth attending four of the 37 schools. Threat of licence suspension was associated with a lower likelihood of future smoking intentions among ever-daily smokers. However, differential enforcement of the law may be occurring as African American and Hispanic youth had a higher probability than white youth of receiving a citation. Before drawing firm conclusions, current findings must be replicated with longitudinal data.

official court records is necessary to determine whether minority youth really are more likely than their peers to be adjudicated.

Although the present study extends the literature on youth tobacco use, prevention, and control policies, there are some limitations and directions for future research. Our tolerance for deviance measure was limited to tobacco related tolerance for deviance and did not address more traditional forms of deviance $^{25}$ (for example, aggression and delinquency). Turbin et $a l^{36}$ reported that smoking covaries strongly with a number of other adolescent problem behaviours, such as precocious sexual intercourse, and drug and alcohol use. Future studies should examine the extent to which youth who are cited are tolerant of other forms of deviance, the extent to which they engage in other deviant behaviours, and the pattern of onset of these behaviours to test the secondary deviance hypothesis. It would also be important to examine the context in which the citation was received (that is, incidental to another charge, in violation of school tobacco policies, etc). Further research is necessary to understand who is being cited, where citations are being received, and the circumstances surrounding citation. Finally, findings from this study using cross sectional data must be corroborated by longitudinal research showing the causal relations between threat of licence suspension, receipt of a citation, and vicarious receipt of a citation on future smoking among youth.

In summary, our findings suggest that although threat of driving licence suspension has its intended effects on the future smoking intentions of youth who are committed smokers, self reported citation receipt is not associated with a lower probability of future smoking for most youth. Vicarious citation does not serve as vicarious punishment as it was not associated with a lower likelihood of future smoking intentions. Findings also indicate that the relation between citation related items and youth smoking is not always direct but moderated by tolerance for smoking related deviance. Finally, according to self reports of citation receipt, differential enforcement of the law may be occurring, with minority youth more likely than their white peers to receive an MIP citation.

\section{Authors' affiliations}

N H Gottlieb, A Loukas, M Corrao, Department of Kinesiology \& Health Education, University of Texas at Austin, Austin, Texas, USA

A McAlister, School of Public Health, University of Texas Health Science Center at Houston, Houston, Texas, USA

C Snell, Prairie View A \& M University, Texas, USA

P P Huang, Bureau of Disease, Injury and Tobacco Prevention, Texas Department of Health, Austin, Texas, USA

\section{REFERENCES}

1 US Department of Health and Human Services. Reducing tobacco use: a report of the surgeon general. Atlanta, Georgia: US Department of Health and Human Services, Centers for Disease Control and Prevention, National Center for Chronic Disease Prevention and Health Promotion, Office on Smoking and Health, 2000

2 Wakefield M, Giovino G. Teen penalties for tobacco possession, use, and purchase: evidence and issues. Tobacco Control 2003;12(suppl I):i6-13.

3 Moore L, Roberts C, Tudor-Smith C. School smoking policies and smoking prevalence among adolescents: multilevel analysis of cross-sectional data from Wales. Tobacco Control 2001; 10:117-23.

4 Jason LA, Berk M, Schnopp-Wyatt DL, et al. Effects of enforcement of youth access laws on smoking prevalence. Am J Community Psy 1999;27:143-60.

5 Jason LA, Katz R, Pokorny SB, Engstrom M, et al. The relationship between youth tobacco control enforcement and crime rates in a mid-western county Am J Health Promotion 2000;14:229-31.

6 Livingood WC, Woodhouse CD, Sayre JJ, et al. Impact study of tobacco possession law enforcement in Florida. Health Educ Behav 2001;28:733-48.

7 Woodhouse LD, Sayre JJ, Livingood WC. Tobacco policy and the role of law enforcement in prevention: the value of understanding context. Qualitative Health Research 2001;11:682-92.

8 Lantz PM, Jacobson PD, Warner KE, et al. Investing in youth tobacco control: a review of smoking prevention and control strategies. Tobacco Control 2000;9:47-63

9 Texas Senate Bill 55. Section 161.252. 1997.

10 Smith DW, Colwell B, Zhang JJ, et al. Theory-based development and testing of an adolescent tobacco-use awareness program. Am J Health Behav 2002;26: 137-44

11 Bandura A. Social foundations of thought and action: a social cognitive theory. Englewood Cliffs: Prentice Hall, 1986.

12 Piliavin I, Gartner R, Thornton C, et al. Crime, deterrence, and rational choice. Am Sociological Review 1986;51:101-19.

13 Centers for Disease Control and Prevention. State tobacco activities tracking and evaluation system. www2.cdc.gov/nccdphp/osh/state/..

14 Langer LM, Warheit GJ. Teen tobacco court: a determination of the short-term outcomes of judicial processes with teens engaging in tobacco possession. Adolescent \& Family Health 2000;1:5-10.

15 Centers for Disease Control and Prevention. Best practices for comprehensive tobacco control programs, 1999. Atlanta, Georgia: Department of Health and Human Services, Centers for Disease Control and Prevention, National Center for Chronic Disease Prevention and Health Promotion, Office on Smoking and Health, 1999

16 Task Force on Community Preventive Services. Recommendations regarding interventions to reduce tobacco use and exposure to environmental tobacco smoke. Am J Prev Med 2001;20:10-15.

17 Pentz MA, Sussman S, Newman T. The conflict between least harm and nouse tobacco policy for youth: ethical and policy implications. Addiction 1997;92:1165-73.

18 Kaplan HB, Damphousse KR. Negative social sanctions, self-derogation, and deviant behavior: Main and interactive effects in longitudinal perspective. Deviant Behavior 1997; 18:1-26.

19 Al-Talib NI, Griffin C. Labelling effect on adolescents' self-concept. International Journal of Offender Therapy and Comparative Criminology 1997;38:47-57.

20 Triplett RA, Jarjoura GR. Theoretical and empirical specification of a model of informing labeling. Journal of Quantitative Criminology 1994;10:241-76.

21 Wolfson $M$, Hourigan M. Unintended consequences and professional ethics: criminalization of alcohol and tobacco use by youth and young adults. Addiction 2002;92:1159-64.

22 Ling PM, Landman A, Glantz SA. It is time to abandon youth access tobacco programmes. Tobacco Control 2002;11:3-6.

23 Cismonski J. Blinded by the light: the folly of tobacco possession laws against minors. Wisconsin Medical Journal, 1994;November, 591-8.

24 Downs WR, Robertson JF, Harrison LR. Control theory, labeling theory, and the delivery of services for drug abuse to adolescents. Adolescence 1997;32:1-24.

25 Jessor R, Jessor SL. Problem behavior and psychosocial development: a longitudinal study, 1997, San Diego, California, Academic

26 Texas Department of Health Bureau of Disease, Injury and Tobacco Prevention. Texas tobacco prevention initiative: infrastructure and baseline data. Austin: Texas Department of Health, 2001.

27 Centers for Disease Control and Prevention. Youth tobacco Surveillance United States, 2000. MMWR Morb Mortal Wkly Rep 2001;20(SS-4):1-84

28 Raudenbush SW, Bryk AS, Congdon RT. Hierarchical linear modeling. Lincolnwood, Illinois: Scientific Software International, 1999.

29 Barcikowski RS. Statistical power with group mean as the unit of analysis. Journal of Educational Statistics 1981;6:267-85. 
30 Aiken LS, West SG. Multiple Regression: Testing and interpreting interactions. Newbury Park: Sage Publications, 1991.

31 Kaplan HB, Lin C. Deviant identity as a moderator of the relation between negative self-feelings and deviant behavior. Journal of Early Adolescence 2000:20:150-77.

32 Stiles BL, Liu X, Kaplan HB. Relative deprivation and deviant adaptations: the mediating effects of negative self-feelings. Journal of Research in Crime and Delinquency 2000;37:64-90.

33 Townsend SM, Pokorny AD, Jason LA, et al. An assessment of the relationship between the quality of school-based tobacco prevention programs and youth tobacco use. Journal of Prevention and Intervention in the Community 2002;24:47-61.

34 Cole D. No equal justice: race and class in the American criminal justice system. New York: The New Press, 1999.

35 Barak G, Flavin JM, Leighton PS. Class, race, gender, and crime: social realities of justice in America. Los Angeles: Roxbury, Publishing, 2001.

36 Turbin MS, Jessor R, Costa FM. Adolescent cigarette smoking: health related behavior or normative transgression? Prevention Science 2000;1:115-124.

\section{AD WATCH}

\section{Use of tobacco products to advertise music events in Dunedin, New Zealand, 2003}

D unedin is a university city of around 120000 permanent residents, situated on the south east coast of New Zealand. During the academic year a large number of tertiary students attend the University of Otago. Since the 1990s legislation has banned tobacco advertising and sponsorship in New Zealand.

A promotional poster appeared in Dunedin in May 2003 advertising a dance event in a local nightclub. The poster imitated the design and colours of a Dunhill cigarette packet (see below) and targeted 18-25 year olds.

In contrast to the "upmarket" "Di Lusso", in September 2003 another promotion targeted a different youth music genre. This used the design and colours of the Lucky Strike cigarette packet. Whereas product manufacturers usually jealously protect their "brands", we are not aware of any action by the tobacco companies in these two cases.

\section{H Darling \\ A I Reeder \\ hdarling@gandalf.otago.ac.nz doi: $10.1136 /$ tc. 2004.008128}
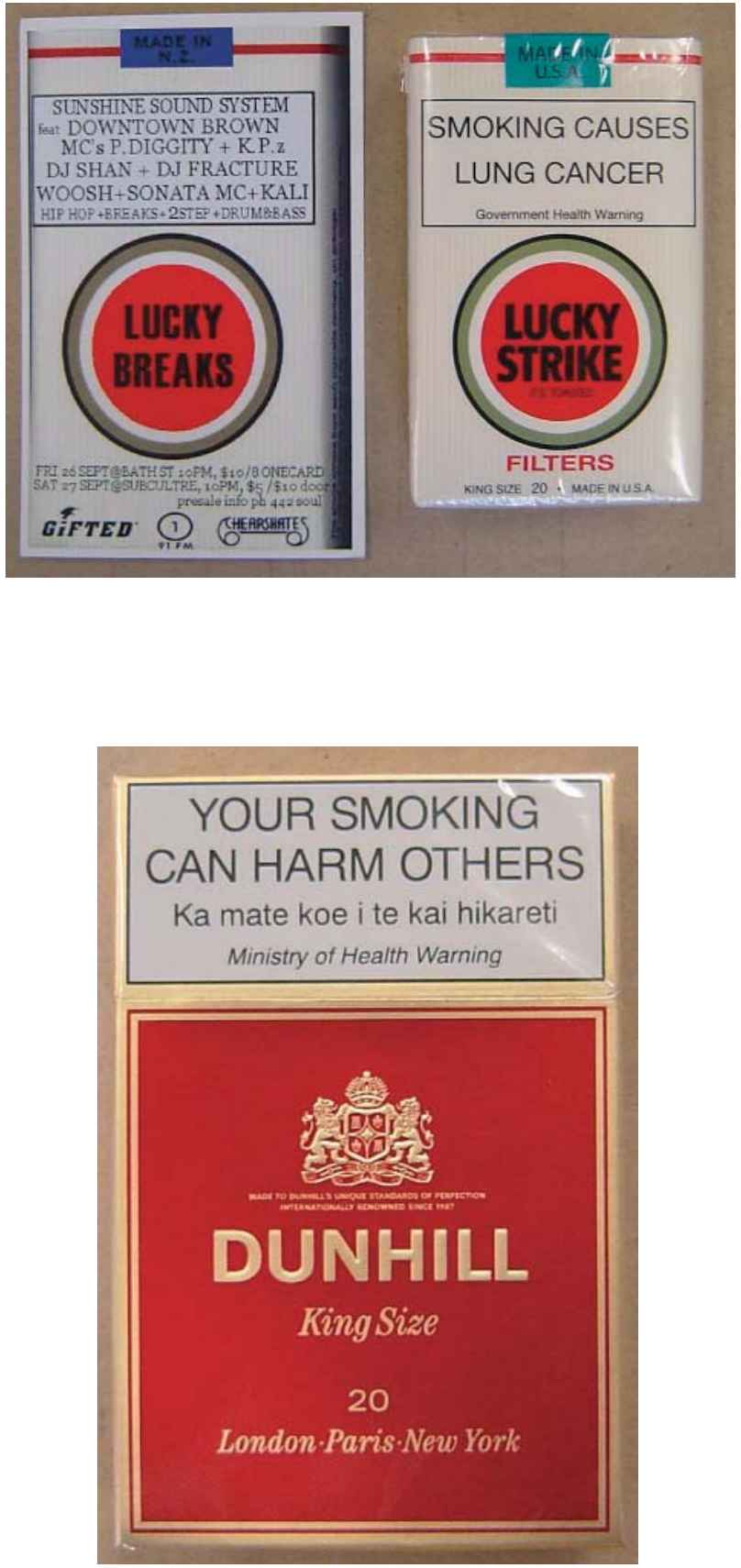